\title{
Emerging antibiotic resistance in honey as a hazard for human health
}

\begin{abstract}
Overtime, intensive use or misuse of antimicrobial agents is considered as the most important factor for the emergence, selection and dissemination of antibiotic resistant bacteria under selective pressure. In this vein, in order to investigate the antibiotic resistance extent, samples from different untreated and unpasteurized honey samples from different botanical sources purchased in bulk from village open markets in Greece were studied. Antibiotic resistance in bacteria isolated from honeys is on the rise. A multiresistance antibiotic profile was effective for most bacterial strains, and pronounced resistance profiles were observed for the commonly used antibiotics. All strains demonstrate resistance to Vancomycin, Ampicillin, Oxacillin and Ceftiofur. High prevalence of S. Aureus, sub. aureus and B. subtilis resistant strains was observed. Metronidazole, Chloramphenicol and Tylosin conserved an almost absent resistance. Systematically monitoring and surveillance of the microbiological quality of selected ecosystems by implementation of a public education campaign must be done, in order to preserve food quality, optimizing sewage treatment and safeguard the public health.
\end{abstract}

Keywords: honey, antibiotic resistance, gram-stained cells, motility
Volume 2 Issue I - 2016

\author{
Bezirtzoglou E,' Voidarou C,' Stavropoulou \\ E, ${ }^{2}$ Kourkoutas Y, ${ }^{3}$ Alexopoulos A,' Plessas S,' \\ Varzakas $\mathrm{T}^{4}$ \\ 'School of Agricultural Development, Laboratory of \\ Microbiology, Biotechnology and Food Hygiene, Democritus \\ University of Thrace, Greece \\ 2Democritus University of Thrace, Greece \\ ${ }^{3}$ Department of Molecular Biology and Genetics, Democritus \\ University of Thrace, Greece \\ ${ }^{4}$ Department of Food Technology, TEl Peloponnese, Greece
}

Correspondence: Eugenia Bezirtzoglou, School of Agricultural Development, Laboratory of Microbiology, Biotechnology and Food Hygiene, Democritus University of Thrace, GR68200 Orestiada, Greece, Email empezirt@agro.duth.gr

Received: August 08, 2015 | Published: February 15, 2016
Abbreviations: VRBL, violet red bile lactose; BAM, bacteriological analytical manual; TT, tetrathionate; SC, selenite cystine; HE, hektoen enteric; BS, bismuth sulfite; PBS, phosphate buffered saline; LPM, lithium chloride-phenylethanol-moxalactam medium

\section{Introduction}

Antibiotics are used both for prophylactic and therapeutic intentions in animals and humans. Antibiotic effectiveness is threatened because of an increase in antibiotic resistant bacteria., ${ }^{1,2}$ When antibiotics are given to battle bacterial infections, most of the bacteria are killed. However, it is well known that antimicrobial drugs can produce alterations on hosts indigenous microbiota selecting resistant organisms, which can appear as opportunistic pathogens. ${ }^{3,4}$

Yet, antibiotics are added on the feedstuff and used as promoters to improve flesh animal production. Antibiotic resistance has spreaded as well in water, food and plant ${ }^{5}$ harboring bacteria.

Moreover, husbandry runoffs and domestic, industrial and hospital sewage effluents aggravate the problem, as surviving resistant bacteria may be passed on other hosts in different ways ${ }^{6,7}$ or on their mutations to new multiplying bacterial generations. As a result, 'pathogenicity islands' are formed harboring multiple drug resistance genes. ${ }^{8}$

During the last years, effective health policy is developed for a constant awareness of the potential danger for over or misuse of antibiotics. Banns are imposed in the use of antibiotics at national level in each country, specific for each microbial ecosystem. On the present paper, in order to investigate the antibiotic resistance profile, samples from different untreated and unpasteurized honey samples from different botanical sources purchased in bulk from village open markets in Greece were studied.

\section{Materials and methods}

\section{Samples collection}

Sixty natural untreated and unpasteurized honey samples purchased in bulk from open markets in villages from the Epirus area in Greece. Our honeys were originated from different botanical sources as following: 15 of coniferous origin, 15 of citrus, 15 of thyme origin and finally 15 polyfloral. Each honey sample was collected in a sterile universal container and kept at $2-8^{\circ} \mathrm{C}$ in the dark, until tested.

\section{Microbiological determinations}

All different samples were collected in triplicate aseptically and weighted before homogenization ( $2 \mathrm{~min}$ at $18,000 \mathrm{rpm}$ in high speed blender), as described previously. Furthermore, decimal dilutions were performed in Ringer's solution and seeded in the following plate media:

Violet Red Bile Lactose (VRBL) agar (Diagnostic Pasteur, Marine La Coquette, France) was used to enumerate the presumptive $E$. coli. Medium incubation was performed at $44.5^{\circ} \mathrm{C}$. The red colonies (diameter $=0.5 \mathrm{~mm}$ ) which appeared within $24 \mathrm{~h}$ were considered as presumptive E. coli. Finally, IMVC test confirmed the presence of the microorganism. 
Baird-Parker agar (Oxoid Ltd., Basingstoke, Hampshire, UK) was used to quantitatively detect $S$. aureus. Representative colonies with typical black appearance and surrounded by clear zone were picked and subjected to Gram-stain, catalase and coagulase tests (Staphylex, Oxoid Ltd., Basingstoke, Hampshire, UK).

Incubation of the plates was performed accordingly to the medium aerobically or anaerobically for $24 \mathrm{~h}$ at $37^{\circ} \mathrm{C}$. Identification of the strains was performed according to their morphological, cultural, and physiological and biochemical characteristics by the procedures described in the Bergey's manual of Systematic Bacteriology. These included microscopic examination of Gram-stained cells; motility; catalase and oxidase reaction; growth in anaerobic conditions. Finally, phenotypic criteria and biochemical tests were performed when necessary. ${ }^{9}$

Salmonella sp. was investigated according to a modification of the Standard method by the Bacteriological Analytical Manual (BAM, 2001). For the pre-enrichment, $25 \mathrm{~g}$ was added to $225 \mathrm{~mL}$ of Lactose broth (LB, pH 7.2) and cultures were incubated at $35^{\circ} \mathrm{C}$ for $24 \pm 2 \mathrm{~h}$. On broth tetrathionate the enrichment step was performed (TT, $\mathrm{pH}$ 8.4) and selenite cystine ( $\mathrm{SC}, \mathrm{pH}$ 7) incubated at $35^{\circ} \mathrm{C}$ for $24 \pm 2 \mathrm{~h}$. Isolations were examined in both media Hektoen enteric (HE) and bismuth sulfite (BS) agars, after incubation at $35^{\circ} \mathrm{C} \pm 2$ for $24 \pm 2 \mathrm{~h}$.

Shigella $\mathrm{sp}$. was investigated according to a modification of the method suggested by Pascual Anderson and Calderón Garcia (2000). For the enrichment step, $25 \mathrm{~g}$ of honey was mixed into $225 \mathrm{~mL}$ of broth for ram negative bacteria $(\mathrm{N}, \mathrm{pH} 7)$. The cultures were incubated at $35^{\circ} \mathrm{C}$ for $16-18 \mathrm{~h}$. Isolations were examined in Hektoen enteric (HE) agar after incubation at $35^{\circ} \mathrm{C}$ for $24-48 \mathrm{~h}$.

For Bacillus sp. each sample was diluted 1:2(w/v) with phosphate - buffered saline (PBS, pH 7.2) and centrifuged at $3000 \mathrm{X}$ g foe $45 \mathrm{~min}$. The suspensions heated at $80^{\circ} \mathrm{C}$ for $15 \mathrm{~min}$, a $100 \mu \mathrm{L}$ aliquot was spread into J-agar (JA). Plates were incubated at $35^{\circ} \mathrm{C}$ for $46 \mathrm{~h}$ under aerobic conditions. Colonies were identified by their morphological appearance in their medium, Gram reaction, shape, and position of spores.

Bacillus cereus was confirmed by presence of large Gram-positive rods with spores that do not swell the sporangium; production of lecithinase and absence of mannitol fermentation on MYP agar; production of acid from glucose anaerobically, reduction of nitrate to nitrite; production of acetylmethylcarbinol (VP-positive); decomposition of L-tyrosine; and finally, growth in the presence of $0.001 \%$ lysozyme, followed by classical biochemical tests. ${ }^{9}$

An aliquot of the Ringer's solution was heated for $10 \mathrm{~min}$ at $80^{\circ} \mathrm{C}$ and from each dilution a second plate of a non selective medium was seeded for detection of the germinated spores forms. Our media were incubated aerobically and anaerobicaly for $48 \mathrm{~h}$ at $37^{\circ} \mathrm{C}$.

To confirm the presence of $C$. perfringens, L.S. (Lactose-Sulfite) medium was used. ${ }^{10}$ The composition of the L.S. broth is as follows: $5 \mathrm{~g}$ tryptic digest of casein; $2.5 \mathrm{~g}$ yeast extract (Difco); $2.5 \mathrm{~g}$ sodium chloride; $2.5 \mathrm{~g}$ lactose; $0.3 \mathrm{~g}$ L-cysteine hydrochloride; $1 \mathrm{~L}$ distilled water. The $\mathrm{pH}$ was adjusted to $7.1 \pm 0.1$ and $9 \mathrm{~mL}$ of the medium was dispensed into tubes. Sterilization was done by autoclaving at $115^{\circ} \mathrm{C}$ for $20 \mathrm{~min}$. Before use, the medium was boiled for $20 \mathrm{~min}$ to reduce the oxygen content and $0.5 \mathrm{~mL}$ of a $1.2 \%$ solution of anhydrous sodium metabisulphite $\left(\mathrm{Na}_{2} \mathrm{~S}_{2} \mathrm{O}_{2}\right)$ and $0.2 \mathrm{~mL}$ of a $1 \%$ solution of ferric ammonium citrate, were added to each tube. The above solutions were prepared and sterilized by filtration $(0.22 \mu \mathrm{m})$ just prior to use. The medium was shaken and from this tube (10-1) two further dilution steps to $10-3$ were made. Incubation was performed aerobically in a waterbath at $46^{\circ} \mathrm{C}$ for $24 \mathrm{~h}$. An aliquot of each sample was heated for $20 \mathrm{~min}$ at $80^{\circ} \mathrm{C}$ for detection of germinated spore forms and for each a L.S. broth was seeded.

For L. monocytogenes, each sample was constituted by three subsamples of $50 \mathrm{~g}$, finely ground in a blender for twominutes. $25 \mathrm{~g}$ of each sample were analyzed according to a modification of the method suggested by Lee \& Mc Clain ${ }^{11}$ and Van Netten et al., ${ }^{12}$ using PALCAM agar (Merck) instead of Lithium chloride-phenylethanol-moxalactam medium (LPM). The procedure included the following steps: primary enrichment (UVM I Listeria enrichment broth, Merck Co.), secondary enrichment (UVM II Listeria enrichment broth. Merck Co.), plating (PALCAM agar) and biochemical identification.

The typical colonies were tested using API Listeria identification kit (BioMerieux. L' Etoile, France) and finally a kit serotyping was performed: Rapid slide agglutination technique was adopted using $L$. monocytogenes $\mathrm{O}$ antisera types 1,4 and poly (Difco, USA).

Honey samples were considered as positive if at least one cfu/g of a given microorganism was discovered and verified in two out of the three repetitions of analysis. All other samples were considered as negatives.

\section{Antibiotic resistance profile}

All isolated B. cereus, C. perfringens, E. coli and S. aureus strains were tested for their antimicrobial activities in Mueller-Hinton agar by applying the antibiotic discs and detected using the disk diffusion method, according to the standards by the National Committee for Clinical Laboratory Standards. ${ }^{13}$ In brief, an aliquot of $100 \mathrm{~mL}$ of an overnight culture was diluted in saline solution to about $1.5 \times 108$ $\mathrm{CFU} / \mathrm{mL}$ ( 0.5 Units of McFarland turbidity standard). Mueller-Hinton agar (Oxoid Ltd., Basingstoke, UK) plates were flooded with this suspension to give confluent colonies. The inoculated plates were allowed to stand at room temperature for $15 \mathrm{~min}$ prior to dispensing the paper disks and the plates incubated accordingly. The diameters of the clear zones around each disk were measured after incubation.

The following concentrations in antibiotic discs were used: Amoxicillin with clavulanic acid $(30 \mu \mathrm{g})$, Erythromycin $(15 \mu \mathrm{g})$, Tylosin $(30 \mu \mathrm{g})$, Metronidazole $(15 \mu \mathrm{g})$, Oxacillin $(10 \mu \mathrm{g})$, Vancomycin $(30 \mu \mathrm{g})$, oxytetracycline $(30 \mu \mathrm{g})$, Ceftiofur $(30 \mu \mathrm{g})$, Ampicillin $(10 \mu \mathrm{g})$, sulfamethoxazole with trimethoprim $(25 \mu \mathrm{g})$, Ciprofloxacin $(5 \mu \mathrm{g})$ and chloramphenicol $(30 \mu \mathrm{g})$.

The Bauer-Kirby technique ${ }^{14}$ was used to determine susceptibility to antibiotics for L. monocytogenes sensitivity of each isolate as 'susceptible', 'intermediate' or 'resistant'.

\section{Statistical analysis}

Chi-square tests were used to determine statistically significant differences in the prevalence of the microbes in the various samples. Mean values of groups were compared by using Kruskal_Wallis and Mann-Whitney tests at 95\% significance level. All statistical analyses were performed with the aid of SPSS v.12 (SPSS, USA).

\section{Results and discussion}

S. aureus was isolated from eight (8) honey samples out of 60 
$(13.3 \%)$ indifferent from their origin (Table 1). E. coli was recovered from 3 samples (5\%), Bacillus sp. from 13 samples (21.7\%) and $C$. perfringens in 17 samples as spore forms $(28.33 \%)$ and in 4 samples $(6.7 \%)$ as vegetative forms. In most of the positive samples vegetative and spore forms of $C$. perfringens were concurred.

*Honey samples were considered as positive if at least one cfu/g of a given microorganism was discovered and verified in two out of the three repetitions of analysis.

Multiresistance to E. coli, pathogenic Staphylococcus and other pathogens isolated of honey has been reported. Vancomycin (12-44\%), Oxacilline (26-58\%), Ciprofloxacin (25-58\%), keeps the sceptre in antibiotic resistance of the different microbial strains isolated from honey, followed by erythromycin (21-52 \%), Amoxicillin with

Table I Occurrence of bacteria (numbers of positive samples), isolated from honey samples

\begin{tabular}{|c|c|c|c|c|c|c|c|c|}
\hline$a / a$ & Origin of sampler & S.aureus & E.coli & $\begin{array}{l}\text { Salmonella } \\
\text { sp }\end{array}$ & $\begin{array}{l}\text { Shigella } \\
\text { sp. }\end{array}$ & Bacillus sp. & \multicolumn{2}{|c|}{ C.perfringens } \\
\hline 2 & Citrus origin & 1 & - & - & - & 2 & 1 & 1 \\
\hline 4 & Polyfloral honey & 3 & - & - & - & 4 & 2 & 6 \\
\hline & Total & 8 & 3 & - & - & 13 & 4 & 17 \\
\hline
\end{tabular}

Table 2 Percentage of resistant strains isolated from honey samples

\begin{tabular}{|c|c|c|c|}
\hline Strain & Sample & Antibiotic compound & $\%$ of Resistant \\
\hline & & Vancomycin & 42 \\
\hline & & Erythromycin & 46 \\
\hline & & Ampicillin & 39 \\
\hline & & Oxacillin & 35 \\
\hline & & Ciproflaxacin & 27 \\
\hline & & Cortimethoxazole & 39 \\
\hline \multirow[t]{7}{*}{ S. aureus } & Honey & with Trimethoprim & \\
\hline & & Oxytetracycline & 26 \\
\hline & & Ceftiofur & 24 \\
\hline & & Amoxicillin with Clavulanic Acid & 30 \\
\hline & & Tylosin & 9 \\
\hline & & Chlolamphenicol & 8 \\
\hline & & Metronidal & 9 \\
\hline
\end{tabular}

clavulanic acid $(21-42 \%)$, cotrimoxazole with trimethoprim (22$46 \%)$, Ampicillin (23-46\%), oxytetracycline (15-26\%), and finally ceftiofur (18-37\%). E.coli and S.aureus strains seem to present the highest multi-antibiotic associated resistance.

Finally, L. monocytogenes was found in one sample (1.7\%) and in low density $(1 \mathrm{cfu} / 25 \mathrm{~g})$. In general, the various bacterial populations were relatively low, ranged from $0.69 \mathrm{log} \mathrm{cfu} / \mathrm{g}$ to $1.41 \mathrm{log} \mathrm{cfu} / \mathrm{g}$ and distributed evenly among the samples.

All isolated strains demonstrate resistance to Ampicillin, Oxacillin and Ceftiofur. The pattern of our isolates against the other studied antibiotics was variable. However, high prevalence of $S$. Aureus, sub. aureus and B. cereus resistant strains was observed (Table 2). 
Table Continued

\begin{tabular}{|c|c|c|c|}
\hline Strain & Sample & Antibiotic compound & $\%$ of Resistant \\
\hline \multirow{13}{*}{ S. aureus subsp. anaerobius } & \multirow{13}{*}{ Honey } & Vancomycin & 34 \\
\hline & & Erythromycin & 36 \\
\hline & & Ampicillin & 12 \\
\hline & & Oxacillin & 48 \\
\hline & & Ciproflaxacin & 24 \\
\hline & & Cortimethoxazole & 22 \\
\hline & & with Trimethoprim & \\
\hline & & Oxytetracycline & 15 \\
\hline & & Ceftiofur & 16 \\
\hline & & Amoxicillin with Clavulanic Acid & 33 \\
\hline & & Tylosin & 8 \\
\hline & & Chlolamphenicol & 7 \\
\hline & & Metronidal & 17 \\
\hline \multirow{12}{*}{ E. coli } & \multirow{12}{*}{ Honey } & Vancomycin & 31 \\
\hline & & Erythromycin & 21 \\
\hline & & Ampicillin & 56 \\
\hline & & Oxacillin & 58 \\
\hline & & Ciproflaxacin & 69 \\
\hline & & Cortimethoxazole & 46 \\
\hline & & with Trimethoprim & \\
\hline & & Oxytetracycline & 15 \\
\hline & & Ceftiofur & 18 \\
\hline & & Amoxicillin with Clavulanic Acid & 21 \\
\hline & & Tylosin & 11 \\
\hline & & Chlolamphenicol & 7 \\
\hline \multirow{14}{*}{ B. cereus } & \multirow{14}{*}{ Honey } & Metronidal & 13 \\
\hline & & Vancomycin & 27 \\
\hline & & Erythromycin & 25 \\
\hline & & Ampicillin & 23 \\
\hline & & Oxacillin & 25 \\
\hline & & Ciproflaxacin & 56 \\
\hline & & Cortimethoxazole & 34 \\
\hline & & with Trimethoprim & \\
\hline & & Oxytetracycline & 18 \\
\hline & & Ceftiofur & 30 \\
\hline & & Amoxicillin with Clavulanic Acid & 24 \\
\hline & & Tylosin & 10 \\
\hline & & Chlolamphenicol & 6 \\
\hline & & Metronidal & 10 \\
\hline \multirow{13}{*}{ C.perfringens } & \multirow{13}{*}{ Honey } & Vancomycin & 12 \\
\hline & & Erythromycin & 52 \\
\hline & & Ampicillin & 36 \\
\hline & & Oxacillin & 26 \\
\hline & & Ciproflaxacin & 39 \\
\hline & & Cortimethoxazole & 40 \\
\hline & & with Trimethoprim & \\
\hline & & Oxytetracycline & 21 \\
\hline & & Ceftiofur & 37 \\
\hline & & Amoxicillin with Clavulanic Acid & 42 \\
\hline & & Tylosin & 11 \\
\hline & & Chlolamphenicol & 10 \\
\hline & & Metronidal & 17 \\
\hline
\end{tabular}

Citation: Bezirtzoglou E, Voidarou C, Stavropoulou E, et al. Emerging antibiotic resistance in honey as a hazard for human health.J Bacteriol Mycol Open Access. 20I6;2(I):6-I2. DOI: I0.15406/jbmoa.20I6.02.000I2 
A multiresistant L. monocytogenes was discovered only in one sample of polyfloral honey. This strain developed resistance to Ampicillin, Oxacillin, Ciprofloxacin, Ceftiofur, Amoxicillin with clavulanic acid and sulfomethoxazole with trimethoprim.

Originally, flower nectar collected by bees mouth mixed with special enzymes in the bees saliva turns into honey. Honey is considered to be a healthy product and a miraculous food without developing side effects. Rural population in Greece traditionally manufactures unpasteurized honey and honey derived products. These products are considering being of high nutritional quality and value are fed commonly to infants as honey is believed to have antimicrobial capacities.

Antibacterial properties of honey have stimulated the interest of many researchers ${ }^{1-4}$ during the last decades. Honey has unique properties that render it bacteriostatic and bactericidal. Honey is reported as wound healing. ${ }^{15}$ It was also given as a gastrointestinal remedy from the very old years until now days. ${ }^{5,15}$

The health benefits of honey depend on the quality of the honey and on the nectar botanical source. ${ }^{16,17}$ Besides its beneficial role, honey seems to hide some negative effects due to the presence of rare bacteria colonizing it. Spore-forming bacteria are usually found in honey, such as Bacillus and Clostridium always recovered in low levels. ${ }^{17}$ Staphylococcus or Enterobacteriaceae found occasionally seems to be secondary contaminants of the product coming from the air, environment, food handling or equipment. ${ }^{18}$

The occurrence of antibiotic-resistant bacteria in foods is a potential health hazard, as resistance can be transferred among bacteria. Irrational and extensive use of antimicrobial agents has led to an increase in the rate of resistant strains of bacteria whether they come from the environment or from clinical sources associated with human infection. ${ }^{19}$ Antibiotic resistance in bacteria may be an intrinsic trait, or it may be acquired. More specifically, genes which are responsible for antibiotic resistance are usually located on the chromosomes of the environmental strains. ${ }^{20,21}$

In recent surveys, it has been established that these genes also exist in plasmids that can easily be transferred to human pathogens. ${ }^{19}$ The majority of antibiotics used in veterinary practice for the treatment of animal infections as well as growth factors included in animal feed additives, which are partially metabolized, excreted and absorbed into plant tissues and aquatic environments. ${ }^{22}$ Resistant bacteria are transferred from food to humans via the food chain, after handling. Antibiotics are also used in aquaculture and agriculture in order to increase the productivity of animals and plants.

Our interest is focused on unpasteurized raw honey associated antibiotic resistance, as in our knowledge there not many studies exploring honey microflora antibiotic profile, ${ }^{5,6}$ which could constitutes an important public health hazard. ${ }^{18}$

In this vein, the antibiotic resistance patterns of our bacterial isolates were performed. The antibiotic resistance patterns of our isolates were performed. A total of 12 antibiotics, as described in material and methods were studied for resistance of isolates such as, C. perfringens, E. coli, S. aureus and B. cereus (Table 2).

A multiresistance antibiotic profile was effective for most bacterial strains, and pronounced resistance profiles were observed for the commonly used antibiotics. All strains demonstrate resistance to
Ampicillin, Oxacillin and Ceftiofur. The pattern of our isolates against the other studied antibiotics was variable.

Antibiotic multiresistance to E. coli, pathogenic Staphylococcus and other pathogens isolated of honey has been reported. E.coli and S.aureus strains seem to present the highest multi-antibiotic associated resistance. Specifically, high prevalence was observed for S. Aureus, sub. aureus and B. cereus resistant strains.

S.aureus vancomycin resistant was shown positive in a restrict amount of samples. As known, it is a pathogenic bacterium of importance in hospitals and community.

However, in recent years its spreading is reported worldwide in livestock and food mainly of animal origin. ${ }^{23}$ People working with live stock farm animals seem to be at a potential risk of becoming carriers of these strains. Bees gather nectar juice in the heart of the flowers or pollen from anthers of flowers.

A multi-resistant microbial flora is indigenous to flowers ${ }^{24}$ and moreover, flowers and plants are exposed to the environmental microflora which as discussed contains multiple antibiotic resistant species. Inhabitants of the environmental ecosystems; soil, waters, plants and their foliage and they became opportunistic pathogens for humans. Specific adaptation to their natural environment and possible mutations seem to arm these strains against the development of antibiotic resistance.

A multiresistant L. monocytogenes was discovered only in one sample of polyfloral honey. This strain developed resistance to Ampicillin, Oxacilline, Ciprofloxacin, Ceftiofur, Amoxicillin with clavulanic acid and sulfomethoxazole with trimethoprim. Albeit the high observed resistance profile, Metronidazole, chloramphenicol and Tylosin conserved an almost absent resistance.

Multi-resistance in hospitalized patients and outpatients have been reported. ${ }^{25}$ The case of outpatients is somewhat interesting, as these patients had not received systematically antibiotics, the observation of frequent multiresistance was not expected in this group of patients. The reason for the resistance patterns observed may be due to the food ingested. It is of substantial interest to note that in our country for improving the quality of animals, antibiotics are added in their food. Antibiotics could be present at high levels in animals and their products consumed by man. It is then conceivable and understoodable, the presence of multiresistance observed in most of our isolates, and in conclusion, it should not be underestimated.

The comparison of similar strains reveals significantly higher total resistance to the environmental ecosystem than to the clinical ones. ${ }^{26}$ Recently, the in vitro bactericidal activity of a medical grade honey (sterilized) has been reported to be effective even upon the antibioticresistant bacteria. ${ }^{27}$

As mentioned, honey microenvironment is not favorable to the persistance of bacteria. Bacteria isolated from honey seem to be associated with the origin of the sample, the quality of the honey and its hygienic status. ${ }^{17}$ Plant origin of honey seems to be associated also to the bacterial load (Table 1). Polyfloral honey as they contains more floral ingredients carrying the microflora of all their constituents. Our results showed a higher bacterial multiresistance to this composite microflora.

Coniferous honey come in second position in terms of bacteria, followed by Thyme and Citrus honey. Coniferous plants and seeds are 
related with high incidence damping-off diseases by their indigenous bacteria due to their abundant microflora. ${ }^{28}$

Thyme and Citrus plants are carrying less bacteria as result of their strong essentials oils which show high antimicrobial activities ${ }^{29}$ through this study, it is reported that different human activities provide environments that select for resistant strains and encourages the transfer of genetic information from unrelated bacterial species. ${ }^{17,30}$

An effective and systematic surveillance strategy is necessary to preserve dissemination of multi-drug resistant microorganisms by imposing strict hygienic rules by legislation. ${ }^{31}$

Since the food origin of some human infections is now recognized, it is thus crucial to test systematically foods, especially those which are not sterilized before consumption for development of antibiotic resistance, in order to establish corrected actions and measures preserving from spreading of antibiotic multiresistant strains.

Habits and techniques associated to the nectar and pollen gathering from plants seems to be of great importance. Bee workers are often illiterate and naive of good collection practices. Monitoring and education should be important to ensure high quality honey.

\section{Acknowledgements}

None.

\section{Conflict of interest}

The author declares no conflict of interest.

\section{References}

1. Mollan, Peter C. The antibacterial activity of honey:1. The nature of the antibacterial activity. Bee World. 1992;73(1):5-28.

2. Mollan, Peter C. The antibacterial activity of honey: 2. Variation in the potency of the antibacterial activity. Bee World. 1992;73(2):59-76.

3. Sackett G. Honey as a carrier of intestinal diseases. USA: Colorado State University; 1919. p.18-30.

4. Smith MR, McCaughey WF, Kemmerer AR. Biological effects of honey. $J$ Api Res. 1969;8(2):99-110.

5. Stomfay Stitg J. Honey; an ancient yet modern medicine. Science Counrellor. 1960;23:110-125.

6. Zumla A, Lulat A. Honey- a remedy rediscovered. $J$ R Soc Med. 1989;82(7):384-385.

7. Kumar K, Gupta SC, Baidoo SK, et al. Antibiotic uptake by plants from soil fertilized with animal manure. J Environ Qual. 2005;34(6):2082-2085.

8. Alexopoulos A, Voidarou C, Stefanis C, et al. Antibiotic resistance profiles and integrons in Enterobacteriaceae from the riverside of Evros-Ardas with respect to chemical and waste pollution. Micr Ecol Health Dis. 2006;18(3-4):170-176

9. Warren BR, Parish ME, Schneider KR. Shigella as a foodborne pathogen and current methods for detection in food. Crit Rev Food Sci Nutr. 2006;46(7):551-567.

10. Bezirtzoglou E, Romond C. Rapid identification and enumeration of $C$. perfringens in the human faecal flora. MicrEcol H Dis. 1990;3(3):159163.
11. Lee WH, McClain D. Improved Listeria monocytogenes selective agar. Appl Environ Microbiol. 1986;52(5):1215-1217.

12. Netten Van P, Perales I, van de Moosdijk A, et al. Liquid and solid selective differential media for the detection and enumeration of $L$. monocytogenes and other Listeria spp. Int J Food Microbiol. 1989;8(4):299-316.

13. National Committee for Clinical Laboratory Standards. Methods for antimicrobial susceptibility testing of anaerobic bacteria. 4th ed. USA: NCCLS publication no. M11-A4, Approved standard; 1997.

14. Traub WH. Simple screening method for gram-positive bacterial betalactam antibiotic tolerance on routine laboratory Bauer-Kirby antibiogram plates. Chemotherapy. 1982;28(2):110-118.

15. Bonvehi JS, Manzanares AB, Vilar JMS. Quality evaluation of broom honey (Spartocyticus supranubius L) produced in Tenerife. J Science Food Agriculture. 2004;84(10):1094-1104.

16. Blomfield R. Honey for decubitus ulcers. JAMA. 1973;224(5):905-910.

17. Tsekoura F, Alexopoulos A, Stefanis C, et al. Aerobic and anaerobic bacteriology of Greek honeys. Greece: $2^{\text {nd }}$ Biennial International Congress on Bioprocesses in Food Industries (ICBF-2006), Patras; 2006.

18. Skoufos I, Voidarou C, Bezirtzoglou E, et al. Effects of machine-miking on the bacterial flora of teat duct and mammary gland of ewes. Journal of Veterinary Medicine Series B. 2006;53(10):499.

19. Baquero F, Martinez JL, Canton R. Antibiotics and antibiotic resistance in water environments. Curr Opin Biotechnol. 2008;19(3):260-265.

20. D'Acosta VM, McGrann KM, Hughes DW, et al. Sampling the antibiotic resistome. Science. 2006;311(5759):374-377

21. Fajardo A, Martinez Martin N, Mercadillo M, et al. The neglected intrinsic resistome of bacterial pathogens. PLoS One. 2008;3(2):e1619.

22. Dolliver H, Gupta S. Antibiotic losses in leaching and surface runoff from manure-amended agricultural land. J Environ Qual. 2008;37(3):12271237.

23. Bezirtzoglou E, Alexopoulos A, Voidarou C. Apparent antibiotic misuse in environmental ecosystems and food. Micr Ecol Health Dis. 2008;20(4):1-

24. Kates SG, McGinley KJ, Larson EL, et al. Indigenous multiresistant bacteria from flowers in hospital and non-hospital environments. Am J Infection Control. 1991;19(3):156-161.

25. Yu HS, Lee JC, Kang HY, et al. Changes in gene cassettes of class 1 integrons among Escherichia coli isolates from urine specimens collected in Korea during the last two decades. J Clin Microbiol. 2003;41(12):54295433.

26. Mantzourani I, Panopoulou M, Theodoridou I, et al. Comparative Antimicrobial Susceptibility Profiling of Tigecycline and other Antibiotics against Clinical and Environmental Isolates. Int J Curr Microbiol App Sci. 2015;4(4):384-396.

27. Wakman PH, Van den Akker JP, Guglu A, et al. Medical-frade honey kills antibiotic resistance bacteria in vitro and eradicates skin colonization. Clin Inf Dis. 2008;46(11):1677-1682.

28. Shung Chang J, Chen CC. Microflora of coniferous seeds in Taiwan Botanical Studiese journal. 1964

29. Fournomiti M, Kimbaris A, Mantzourani I, et al. Antimicrobial activity of essential oils of cultivated oregano (Origanum vulgare), sage (Salvia officinalis), and thyme (Thymus vulgaris) against clinical isolates of Escherichia coli, Klebsiella oxytoca, and Klebsiella pneumoniae. Microb Ecol Health Dis. 2015;26:23289. 
30. Bryan A, Shapir N, Sadowsky MJ. Frequency and distribution of 31. Voidarou C, Alexopoulos A, Plessas S, et al. Antibacterial activity of tetracycline resistance genes in genetically diverse, non-selected, and non clinical Escherichia coli strains isolated from diverse human and animal sources. Appl EnvironMicrobiol. 2004;70(4):2503-2507. different honeys against pathogenic bacteria. Anaerobe. 2011;17(6):375379 